IZA DP No. 6044

Work-Related Health in Europe: Are Older Workers More at Risk?

Melanie K. Jones

Paul L. Latreille

Peter J. Sloane

Anita V. Staneva

October 2011 


\title{
Work-Related Health in Europe: Are Older Workers More at Risk?
}

\author{
Melanie K. Jones \\ Swansea University \\ Paul L. Latreille \\ Swansea University \\ and IZA \\ Peter J. Sloane \\ Swansea University, \\ NILS, Flinders University and IZA
}

Anita V. Staneva

Swansea University

Discussion Paper No. 6044

October 2011

\author{
IZA \\ P.O. Box 7240 \\ 53072 Bonn \\ Germany \\ Phone: +49-228-3894-0 \\ Fax: +49-228-3894-180 \\ E-mail: iza@iza.org
}

\begin{abstract}
Any opinions expressed here are those of the author(s) and not those of IZA. Research published in this series may include views on policy, but the institute itself takes no institutional policy positions.

The Institute for the Study of Labor (IZA) in Bonn is a local and virtual international research center and a place of communication between science, politics and business. IZA is an independent nonprofit organization supported by Deutsche Post Foundation. The center is associated with the University of Bonn and offers a stimulating research environment through its international network, workshops and conferences, data service, project support, research visits and doctoral program. IZA engages in (i) original and internationally competitive research in all fields of labor economics, (ii) development of policy concepts, and (iii) dissemination of research results and concepts to the interested public.
\end{abstract}

IZA Discussion Papers often represent preliminary work and are circulated to encourage discussion. Citation of such a paper should account for its provisional character. A revised version may be available directly from the author. 
IZA Discussion Paper No. 6044

October 2011

\section{ABSTRACT}

\section{Work-Related Health in Europe: Are Older Workers More at Risk?*}

This paper uses the fourth European Working Conditions Survey (2005) to address the impact of age on work-related self-reported health outcomes. More specifically, the paper examines whether older workers differ significantly from younger workers regarding their jobrelated health risk perception, mental and physical health, sickness absence, probability of reporting injury and fatigue. Accounting for the 'healthy worker effect', or sample selection in so far as unhealthy workers are likely to exit the labour force - we find that as a group, those aged 55-65 years are more 'vulnerable' than younger workers: they are more likely to perceive work-related health and safety risks, and to report mental, physical and fatigue health problems. As previously shown, older workers are more likely to report work-related absence.

JEL Classification: I0, J28, J81, J20

Keywords: mental health, physical health, absence, fatigue, endogeneity, healthy worker selection effect

Corresponding author:

Paul L. Latreille

School of Business and Economics

Richard Price Building

Swansea University

Singleton Park

Swansea, SA2 8PP

United Kingdom

E-mail: p.I.latreille@swansea.ac.uk

\footnotetext{
* The authors gratefully acknowledge the financial support of the European Commission under the Seventh Framework Programme, Theme HEALTH-2007-4.2-3 (Grant agreement no.: 200716).
} 


\section{Introduction}

In modern society, work provides the material wherewithal for life and well-being, but can also carry risks for individual health (Waddell et al., 2006; OECD, 2008). Recent studies suggest there are specific characteristics of work that may be especially problematic for older workers (Griffiths, 1999). However, most research into the relationships among work conditions and health has not explored age as a variable of explicit interest, instead treating it as a potential confounding factor, either 'partialled out' statistically or simply ignored (Griffiths, 2000) ${ }^{1}$. As the proportion of the workforce aged 55 and over continues to grow - a trend given additional impetus by recent or proposed raises in the (statutory) retirement age in several European countries including the UK, France, Germany, Spain, Italy and Greece - closer examination of this issue becomes imperative.

The aim of the current study is therefore to investigate age differences in a battery of self-reported $^{2}$ work-related health measures using cross-country data from the 2005 European Working Conditions Survey (EWCS). Five work-related 'outcomes' are used to assess overall work-related health and well-being: health and safety risk perception; mental and physical ill health; sickness absence; injury rates; and work-related fatigue. Crucially, we compare the experiences of younger, prime age and older workers ${ }^{3}$ to assess their relative risks in respect of each of these various health outcomes which are linked in our empirical analysis to exposure to physically, ergonomically and psychosocially hazardous working conditions. However, since the EWCS contains information on working respondents only, a key issue for our analysis is to account for a potential 'healthy worker effect'. This effect arises if older workers still in the labour market have better underlying health than those who

\footnotetext{
${ }^{1}$ Debrand and Lengagne (2008) in contrast, focus on the impact of various working conditions on the health of older workers only.

${ }^{2}$ While our data have a number of strengths, including multiple outcome measures (see below), an acknowledged concern of self-reported data is the risk of reporting bias (Van den Berg et al., 2010).

${ }^{3}$ These groups are defined as age 15-35, 36-54 and 55-65 respectively. The normal retirement age in 2005 does however differ among European countries. For men, this is 65 years in all countries except France, where it is 60 years. For women a more divergent pattern applies. In Austria, France, Greece and Italy it is 60 years, in Belgium 62, in Switzerland 64, while it is 65 in Germany, the Netherlands, Denmark, Spain and Sweden (Kalwij and Vermeulen, 2008).
} 
leave employment, a source of selection bias (Li and Sung, 1999). We address this issue by making use of an external data source - the European Social Survey (ESS) - in order to account for labour market non-participation, adapting the Wolinsky et al., (2009) reweighting approach based on propensity scores for being in employment. In particular, the employment model estimated with 2004/05 ESS data is used to predict probability weights, and the inverse of these are then used to weight the observations in our main EWCS-based data models.

This study thus contributes to the literature in three main ways. First, by focusing on work-related health complaints among younger and older workers, we address an issue with important policy implications. Many countries have been attempting to develop policies to encourage older workers to remain longer in the labour market and delay retirement (Cai and Kalb, 2006). Clearly, the success of these policies will depend on better understanding of the outcomes for older individuals of working age and aspects of their occupational health and safety. Second, our data enable us to control more comprehensively for the influence of job characteristics and the workplace on individuals' health than has sometimes been possible hitherto, and to do so using international data. Finally, from a technical perspective, we account simultaneously for the potential endogeneity of working conditions and for the 'healthy worker effect'.

The remainder of the paper is organized as follows. Section 2 reviews the relevant literature. Section 3 documents the datasets, while in Section 4 we describe the empirical methodology. Section 5 presents the empirical results, and finally Section 6 concludes. 


\section{Background literature}

While the links between work environment and poor health are well-established within the occupational medicine literature, fewer researchers have paid attention to the explanation for, and prediction of, age-related differences in work outcomes (Warr, 1992 is an exception). One strand of literature demonstrates that older workers are at higher risk in relation to self-reported health problems and long-term sickness absence (Niedhammer et al., 2008). Age-related deterioration in various physiological systems is well-established: being old denotes a higher probability of suffering from health conditions and multiple health complaints (Winblad et al., 2001). Mitchell (1988) concludes that prime-age workers and older workers do not seem to have different patterns of job-related temporary disabilities. However, those aged 65 and over appear more likely to suffer work-related permanent disabilities and fatalities on the job. Some indication of this picture is revealed by information on the health of older workers and ill-health early retirement. Data from countries such as the Netherlands and Sweden, indicate that ill-health early retirement is increasingly made on the grounds of stress and musculoskeletal disorders (Goedhart, 1992). Conversely, older employees have been shown to have lower absence and turnover rates than younger workers, and to be more satisfied with their job (Hogarth and Barth, 1993). Taimela et al. (2007), investigating how age and self-reported health problems are associated with sickness absence within a sample predominantly employed in physical work, find that younger workers have a higher propensity for sickness absence than their older counterparts.

When accident and injury studies are reviewed, there is similarly contradictory evidence on the outcomes of work-related injury for older workers. Some studies report that older workers require more time off work to recover following an injury and have more disabling conditions than younger workers (Rogers and Wiatrowski, 2005), but in general, older workers are seen as having a lower accident risk than younger workers (Benjamin and 
Wilson, 2005). The lower accident rates among older workers may result from more accident-prone individuals either leaving the workforce earlier or working in a less dangerous work environment (Laflamme et al., 1996) as a result of previous accidents and injuries sustained earlier in their working life. Ostlin (1988) reports a flattening or even decrease in injuries in the older age groups (55+ years), which he explains through the healthy worker effect.

Several cross-sectional studies demonstrate that newly hired workers with limited experience are more likely to suffer an injury than workers with longer job tenures (Butani, 1988). However, Bohle et al. (2010) indicate that these differences are likely to diminish as experienced older workers suffer job displacement due to downsizing or taking temporary jobs, and the shift to a more flexible labour market is likely to decrease the overall advantages that accrue from longer job tenure. Also, older workers are more at risk of fatal accidents (Grandjean et al., 2006) and take longer to recover from non-fatal serious injuries (Laflamme and Menckel, 1995).

As well as the healthy worker effect, there are a number of complicating methodological/measurement issues. Among the key findings of the literature is the tendency of many older individuals to normalize their disease (Hudak et al., 2002), to minimize or even ignore their health problems (Idler, 1993), and to rate their general health status positively than younger persons (Cockerham et al., 1983). Possible explanations include ageing effects (Idler, 1993), cohort differences (Folkman et al., 1987), the relationship between experience and understanding of risk differentials (Viscusi, 2004) and the use of historical frames of reference in judging work demands (Broersen et al., 1996). In addition there may be a habituation effect whereby regular exposure to a risk reduces its perceived severity (Leoni, 2010). 
The 'decrement theory of ageing' argues that crucial physical and cognitive changes occur with age (Giniger at al., 1983), and we would expect these changes to negatively affect worker's health and coping resources. According to this perspective, a higher level of job hazards is expected to have a stronger adverse effect on health among older people than their younger counterparts. A second perspective argues that as people age, they gain wisdom and experience allowing them to become more effective in the use of their coping resources (Shirom et al., 2008).

Possibly reflecting the first of these perspectives, older employees in very strenuous working conditions or with lower than average work capacity and with health problems may be more likely to change their job to one with fewer hazards or to leave the labour force altogether. Warr (2000) shows that age is also positively associated with an increased preference for physical security, salary and opportunities for skill utilization, and negatively associated with the importance of high job demands, job variety, feedback and provision of external goal assignments. Furthermore, health status and working conditions are important variables that explain early retirement (Lumsdaine and Mitchell, 1999). Difficult working conditions reduce the productivity of older workers, increase their absenteeism rate and the probability of losing their jobs, and encourage them to leave the employment market (Blanchet, 2005). The remaining employees have a relatively higher work capacity and work in less strenuous conditions, which might explain the decreased incidence of work complaints in the older age categories (Broersen et al., 1996). Pailhé (2005) demonstrates that older workers in France are more protected, with women being protected from physical strain, while men are protected from commercial demands. Protection against physical strain often operates through exclusion from the workforce, particularly through early retirement, rather than reassignment to other positions within the company. Younger people claim to be more exposed to all types of risk at work. 
The relationship between age and subjective well-being is complex and somewhat counter-intuitive. Warr (1992) analyses whether the relationship of age with occupational well-being is linear or non-linear, finding a U-shaped relationship. A longitudinal study by de Lange et al. (2010) examines age-related differences in terms of the cross-lagged relation between work and occupational health. The study indicates the significance and complexity of the interactions between age, work and mental health. However, the authors conclude that is difficult to decide whether the age group differences are determined by age-related variables or 'cohort' effects.

\section{Data and empirical analysis}

Our data come from the 2005 European Working Conditions Survey (EWCS), a cross-sectional survey of working individuals providing detailed information about their job and working environment, including physical and psychosocial risks. The survey involves multi-stage random sampling covering employed and self-employed persons aged 15 years and over. In 2005 it covered 31 countries (the 27 EU Member States, two candidate countries (Croatia and Turkey) and two EFTA countries (Switzerland and Norway)), and collected information on 29,680 workers. Exclusion of respondents with missing information on one or more of the relevant variables reduces our sample size to $17,459^{4}$. All descriptive statistics (Table A1) are derived using cross-national weights corresponding to country-specific shares of the EU employed population. Due to the small sample size in individual countries, national analyses from EWCS are not feasible.

Since the EWCS records only active workers, the selection of less healthy workers out of occupational cohorts or from more exposed to less exposed jobs may result in bias, and the underestimation of health effects (Eisen et al., 1983). In particular, a greater proportion of

\footnotetext{
${ }^{4}$ We include self-employed individuals, who comprise $12.9 \%$ of the sample. Results are not sensitive to their exclusion.
} 
older workers may have left employment due to underlying health changes (see for example, Bound et al. 1999).

In order to examine the effect of this potential bias, an external data source - the 2004/2005 European Social Survey (ESS) is considered. The ESS provides information on the entire population, not just those in work, and includes relevant job-related variables such as past unemployment experience, contract type, sector, occupation, and hours worked, and allows us to estimate an employment probability model. The 2004/05 survey includes over 30 countries, 23 in common with the EWCS. Analysis is therefore restricted to individuals aged between 15 and 65 in these 23 countries $^{5}$ for which there is information on the complete set of relevant variables in both the ESS and EWCS. The final sample size for the ESS sample is 31,825 respondents, of whom 20,960 (65.8\%) are in employment.

Crucially, comparison of explanatory variables used in the employment probability model for both the ESS sample and the EWCS, where the summary statistics for the former are restricted to working individuals for commensurability, reveals similar gender, age and occupational distributions (Table A2). For instance, younger workers (individuals aged 1535) comprise $34.3 \%$ and $37.7 \%$ of both samples. Professionals account for $15.7 \%$ of the ESS sample and $14.9 \%$ of the EWCS sample, while the percentage of respondents performing service tasks is $12.6 \%$ in the EWCS sample and $13.7 \%$ in the ESS sample. Because of these similarities, we are confident in using the ESS to estimate our employment probability model, allowing us to identify working and non-working individuals ${ }^{6}$. The 2005 EWCS remains, however, the main dataset for the substantive analysis, its key advantage being that it contains detailed information to study the effects of working conditions, such as physical environment,

\footnotetext{
5 Austria, Belgium, Switzerland, Czech Republic, Germany, Denmark, Estonia, Spain, Finland, France, UK, Greece, Hungary, Ireland, Italy, Luxembourg, Netherlands, Norway, Poland, Portugal, Sweden, Slovenia and Slovakia.

${ }^{6}$ The surveys do however, have slightly different measures of several variables, most notably health status: an individual in the ESS has good self-reported health if (s)he has self-reported general heath that is 'excellent' or 'very good', whereas an individual in the EWCS is in good health if (s)he reports no health problems over the last 12 months.
} 
hours and patterns of work (night work, shift work), and social and organisational environment, alongside age.

The key dependent variables of interest in this study concern various facets of workrelated health and safety as noted above: perceived health risk, reported health complaints, physical and mental health complaints, sickness absence, injury and fatigue. In relation to the first of these, workers are asked 'Do you think that your health and safety is at risk because of your work?', and we define a dichotomous variable equal to 1 if individuals agree that this is the case and 0 if not. Work-related health complaints are similarly measured as a dichotomous variable, coded 1 for individuals responding in the affirmative to the question: 'Does your work affect your health, or not?' Figure 1 presents both variables separately by age group.

Figure 1: Health and safety risk perception and health complaints, by age group

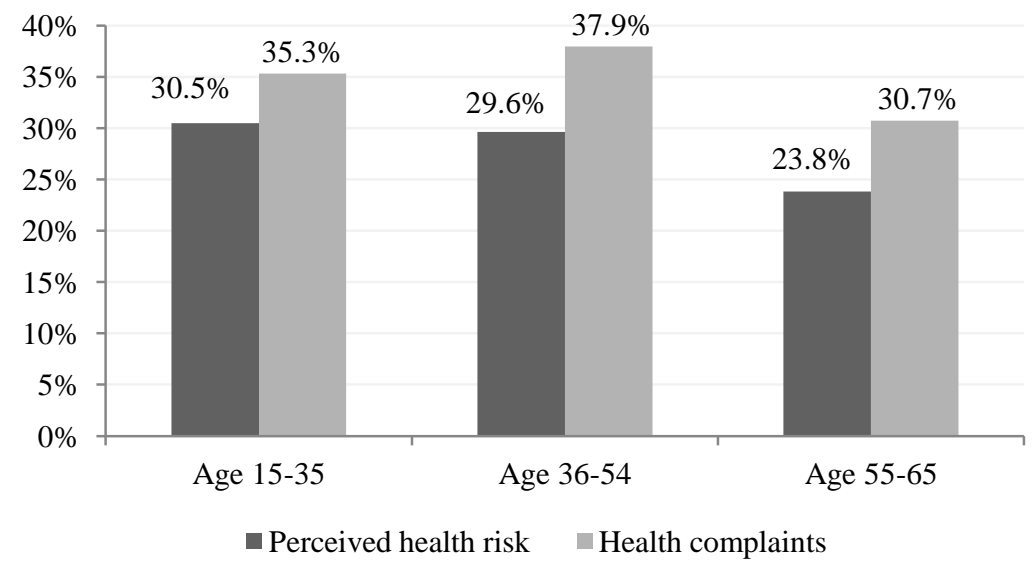

Notes: EWCS 2005. Cross-national weights adjusted.

As can be seen, older workers are on average less likely to consider their workplace as potentially injurious to their health $(23.8 \%$ of older workers compared with $30.5 \%$ of respondents aged between 15 and 35). While recognising the very different nature of the questions, the data also indicate that perceived risk may differ from self-reported, workrelated health complaints, even among older respondents whose experience might be 
expected to allow them adjust their perception of risk: $23.8 \%$ of this group consider their jobs as involving health risks, while $30.7 \%$ of the same group report that their health may have been affected by their working conditions. This suggests that respondents tend to "underestimate" work-related health risk when compared to the actual (self-reported) health impact of the work.

Those indicating that their work impacts on their health are then asked 'How does it affect your health?' and select from a prompted list of health problems, including both physical and mental health symptoms/complaints. The most frequently reported are musculoskeletal disorder-backache $(25.3 \%)$ and muscular pains (23.1\%), stress (23.9\%), fatigue $(23.0 \%)$ and headache $(16.3 \%)$. This information therefore allows us to construct two further (binary) indicators. As a measure of the intensity of mental health problems, we use information on whether work causes stress, sleeping problems, anxiety and irritability, and construct a dummy variable equal to 1 if workers report more than two work-related mental health complaints. Given the self-reported nature of the information, we view this as measuring mild to moderate mental problems. In relation to indicators of work-related physical health complaints, such as hearing, vision, skin, respiratory problems, backache, stomach ache, or muscular pain, we define a respondent's physical health variable taking the value 1 if the worker reports more than two of these problems. Figure 2 shows the incidence of these two measures of work-related mental and physical health, again disaggregating by age groups. 
Figure 2: Incidence of more than two mental and physical health complaints, by age group

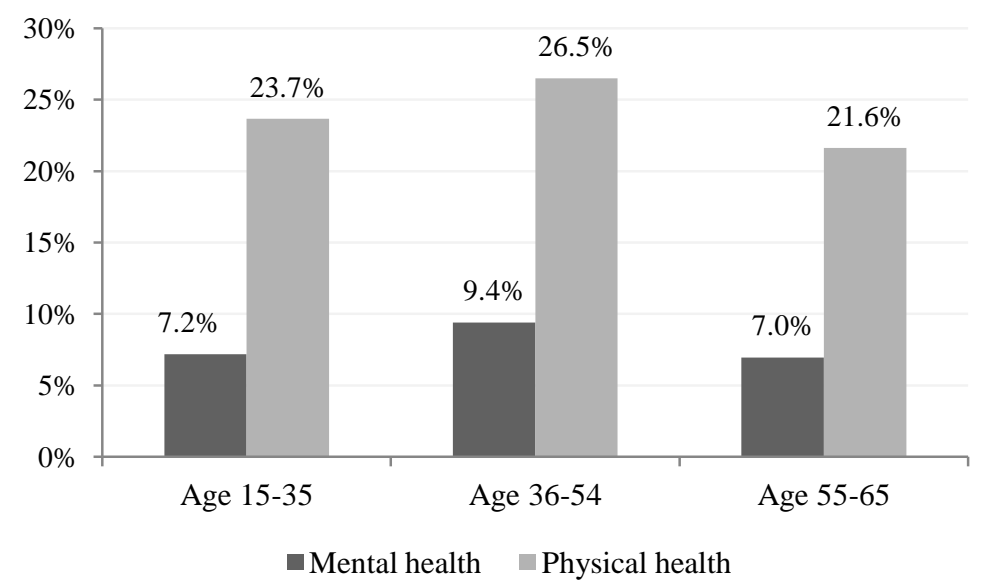

Notes: See notes to Figure 1.

On average $25.0 \%$ of the sample report more than two work-related physical health symptoms and $8.3 \%$ mental health problems. In contrast to the view that older workers may be particularly at risk from exposure to difficult working conditions, they actually report a slightly lower incidence of (multiple) physical and mental health complaints compared with younger and middle-age groups. For instance, $21.6 \%$ of employees aged 55 over report more than two work-related physical health problems; the corresponding figure is $23.7 \%$ for those aged 15-35.

Survey respondents were also asked 'Over the past 12 months how many days in total were you absent from work for reasons of health problems?' and 'Of the days of absence indicated above, can you indicate how many days were attributable to... health problems caused by your work?' From this we construct a further binary dependent variable for sickness absence equal to 1 if respondents reported an absence in the previous year due to work-related health problems. Finally, we define dummy variables for work-related injury and for fatigue equal to 1 in each case if the individual identified injury(ies) or (overall) fatigue respectively among the list of ways in which their work affects their health (see above). 
Our data indicate that older workers are slightly less likely to take sickness absence compared to younger individuals (Figure 3). The injury rate among younger workers is significantly higher when compared with the older age group: on average $11.2 \%$ of employees aged between 15 and 35 years report work-related injury, against 7.1\% of 55-65 year olds. This is in line with the majority of empirical studies on non-fatal injuries (see above), indicating that younger workers have a higher injury rate than the overall rate. The data also show, perhaps more surprisingly, that older workers are substantially less likely to report their work causes fatigue.

Figure 3: Sickness absence, injury and fatigue, by age group

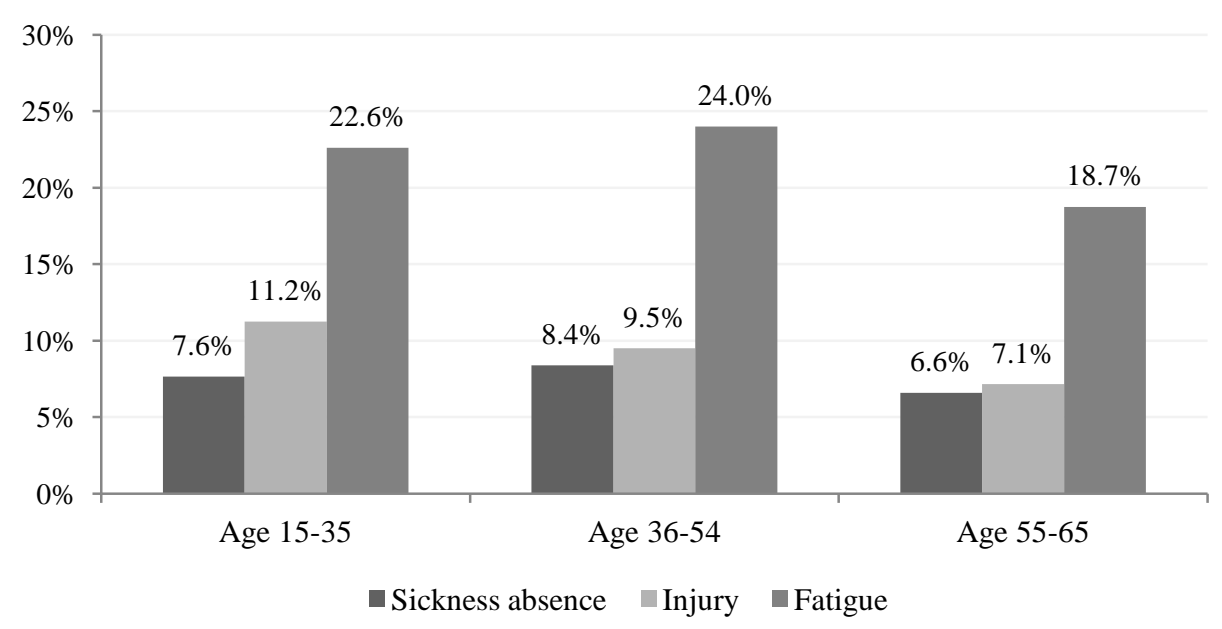

Notes: See notes to Figure 1.

As the above data thus reveal, there are substantial age differences among the various work-related health outcomes variables, which may reflect the sorts of consideration described in the literature section. For example, there is a significant difference in work experience between younger and older age groups, which may contribute to the results above. Older workers report significantly longer tenure, having been with the current employer for an average of 19 years, compared with only 4 years for individuals aged $15-35$. The effect of age and experience might explain the lower perception of workplace risk that we observe among older employees: greater experience of hazards without suffering will arguably lower 
the perceived risk (Leoni, 2010). Of course, these outcome differences may also reflect and endogeneity and selection issues highlighted above.

A key feature of the EWCS survey is that it permits us to identify the extent to which different categories of workers are exposed to various risk factors in the workplace. We distinguish three sets of potential workplace hazards - physical factors (noise, vibration, extreme temperature, smokes, fumes, vapours, radiation, handling chemical products), ergonomic factors (painful positions, carrying heavy loads, repetitive hand or arm movements, standing or walking), and psychological job demands (whether the employee's main job entails working "at very high speed" and "to tight deadlines", whether respondents report having insufficient "time to get the job done", and "can almost never get assistance from colleagues or superiors") ${ }^{7}$. The findings in Table 1 report the proportion of respondents in the EWCS (2005) by age, for each category of risk factor. As can be seen, psychosocial risks are the most commonly reported (the most frequent item being working to tight deadlines), followed by ergonomic risks. Strikingly, older workers report lower exposure levels than their younger counterparts across all three risk categories.

[Table 1 here]

\section{Empirical methodology}

We examine the influence of age on each of our measures of work-related health while controlling for other personal characteristics, job attributes and working conditions. Given the dichotomous nature of the dependent variables, we utilise a discrete choice probability model:

$$
\begin{aligned}
& y_{i}^{*}=\alpha+D_{i} \beta+W C_{i} \gamma+W A_{i} \delta+\varepsilon_{i} \\
& y_{i}= \begin{cases}1 & \text { if } y_{i}^{*}>0 \\
0 & \text { otherwise }\end{cases}
\end{aligned}
$$

\footnotetext{
${ }^{7}$ Summary physical, ergonomic and psychosocial risk variables were constructed as exposure to one or more risk factor within the relevant category. Detailed descriptive statistics of exposure to specific risks are available on request.
} 
where $y_{i}$ represents the realization of a latent variable which captures whether a worker $i$ reports a work-related health complaint measured by one of the following: perceived health risk, health complaints, mental and physical complaints, sickness absence, injury rate and fatigue. Personal characteristics such as age, gender, tenure, are included in $D_{i} \cdot W C_{i}$ contains information on working conditions in the current job (exposure to physical, psychosocial and ergonomic risk factors), while $W A_{i}$ accounts for job characteristics (i.e. working in the public sector, at nights/evenings, discrimination at the workplace, working part-time, occupation) and workplace attributes (firm size). All models include country of residence dummy variables. The main focus here is on the explanatory power of age coefficients.

However, as Mazzolini (2010) and Cottini and Lucifora (2010) have proposed, endogenous selection in safety at work may bias our coefficients since older workers may be less likely to select jobs with high exposure to hazardous and physically demanding conditions. Following the above authors and Arundel et al., (2006), we therefore introduce as instruments two binary variables that are related to high-performance work organization: responsibility for precise quality standards, and discretion in choosing tasks, methods and work pace ${ }^{8}$. Mazzolini (2010) argues that high-performance work organization is characterized by a series of firm practices aimed at increasing employee involvement, discretionary autonomy and responsibility for quality control. Our identifying assumption is that workers in firms which involve precise quality standards or higher levels of autonomy enjoy better working conditions.

Fitting limited dependent variable models with endogenous regressors has received considerable attention in the econometric literature. Building on the results of Amemiya (1978), Newey (1987) developed an efficient method of estimation that encompasses both Rivers and Vuong's (1988) simultaneous-equations probit models. Ultimately, the

\footnotetext{
${ }^{8}$ The Amemiya-Lee-Newey minimum chi2 statistic test of over-identifying restrictions does not favour introducing
} additional instruments such as learning new things at work, problem solving activities, or team working. 
endogenous regressor $\left(W C_{i}\right)$ is treated as a linear function of the instruments, as well as of the other exogenous variables, and the model is jointly estimated using a maximumlikelihood estimator. We consider the following model, which is the case of a single continuous regressor in a binary outcome model:

$$
\begin{aligned}
& y_{i}^{*}=x_{1 i} \beta+W C_{i} \gamma+u_{i} \\
& W C_{i}=x_{1 i} \pi_{1}+x_{2 i} \pi_{2}+v_{i}
\end{aligned}
$$

where $W C_{i}$ is our endogenous working condition indicator. In order to construct a continuous endogenous variable, we perform principal component analysis and extract the first component, which measures, for each observation, the relative individual exposure to physical, psychosocial and ergonomic working conditions; $x_{1 i}$ is a vector of exogenous variables controlling for personal characteristics $\left(D_{i}\right)$ and other job characteristics and workplace attributes $\left(W A_{i}\right)$ as previously described; $x_{2 i}$ contains the two instrumental variables described above that affect $W C_{i}$ but can be excluded from equation (2) as they do not directly affect $y$. By assumption $\left(u_{i}, v_{i}\right) \sim N(0, \Sigma)$ where $\sigma_{11}$ is normalized to one to identify the model. Equation (2) might be referred to as "structural", and this equation is of main interest, and equation (3), a reduced-form equation, serves only as a source of identifying assumptions, providing a check on the strength of the instruments and on the goodness of fit of the reduced form ${ }^{9}$.

In relation to identification, each instrument must satisfy the conditions of relevance and validity. Contrary to the case of continuous dependent variable models, tests of instrumental validity do not exist for limited dependent variable models. A common practice to verify instrumental validity in the IV probit, is the Amemiya-Lee-Newey overidentification test, which tests if the instruments are uncorrelated with the error term; an

\footnotetext{
${ }^{9}$ In Stata, the 'IV probit' routine fits models with dichotomous dependent and continuous endogenous regressors and jointly estimates two equations via maximum likelihood. In fact the routine applies maximum likelihood estimations of Amemiya's generalized least squars estimator (as described in Newey, 1987).
} 
essential condition for the validity of the IVs. In our case, we fail to reject the null hypothesis of the over-identification test, confirming the validity of the instruments. Both instruments are statistically significant in all reduced-form equations confirming their relevance. Finally, we perform the Wald test of exogeneity of working conditions, the null being that the covariance between the reduced-form equation's error and the structural equation's error are uncorrelated $(\rho=0)$ ). Rejection of the null confirms the endogeneity of working conditions in our models.

Finally, focusing on the age differences in self-reported health complaints, there is another important complication related to selection, the so called 'healthy worker effect'. When only active workers are studied, the selection of less healthy workers out of occupational cohorts or from more exposed jobs may result in the underestimation of adverse health effects (Monson, 1986). In principle, when there is differential selection out of employment on the basis of poor health status, bias in the estimation of exposure effects can only be eliminated by a longitudinal study (Punnett, 1996). A number of ways to minimize the healthy worker effect have been proposed, with some authors suggesting that a selection bias correction can be accomplished by a generalization of the inverse probability weighting estimator (Horvitz and Thompson, 1952). Inverse probability weighting can correct for the unrepresentative non-random sampling of potential outcomes by giving less weight to those individuals who have a high probability of their observed treatment, conditional on the set of covariates (Jones, 2007). The current paper adapts the Wolinsky et al. (2009) re-weighting approach based on propensity scores to adjust for selection. The weights are generated as the inverse of the conditional probability of being in employment

Since the EWCS sample is restricted to workers, we estimate the employment probability model using data from the ESS which contains both working and non-working 
individuals ${ }^{10}$. This enables us to generate consistent predictions for employment and hence for the inverse of the employment probability used to re-weight the observations in the probit specifications for self-reported health in our main EWCS data set.

The explanatory variables included in the selection equation include gender, age, selfreported health status ${ }^{11}$, education and number of children. Additional variables in the employment participation probit include a set of occupational dummies ${ }^{12}$ and controls for country fixed-effects.

\section{Results}

Tables 2 and 3 provide the main econometric results for each of our work-related health measures: health and safety risk perception, work-related health complaints; physical and mental health, absence due to work-related health, injury, and fatigue. For ease of interpretation, we report marginal effects throughout. We do not adjust for the cross-national population weighting; results do not depend upon doing so.

\subsection{Unadjusted results}

Our main interest is in the effect of age on work-related health outcomes. Table 2 indicates that, compared to prime age workers, younger workers are less likely to be affected by all work-related health problems with the exception of injury (column (6)). For instance, column (1) of Table 2 indicates that, ceteris paribus, younger workers have a 2.3 percentage point lower probability of perceiving their jobs to be risky (significant at the 10 per cent level) compared with prime age workers, while the probability of reporting work-related health

\footnotetext{
${ }^{10}$ Our model measures individuals in paid work in the last 7 days versus those still in education, unemployed, retired, or household workers.

${ }^{11}$ A problem with using self-reported health in empirical analysis of labour force participation is that it may be endogenous. Since this is not the focus of the current paper we ignore this issue, assuming self-reported health is an unbiased measure of true health.

12 Individuals currently not in employment report their last occupation.
} 
complaints is 5.7 percentage points lower (column (2)). As noted, the only exception to this broad pattern is the finding that younger workers are more likely to suffer from an injury at work, in line with previous literature indicating younger workers to be more accident-prone (Robinson and Smallman, 2006), albeit the marginal effect is very small (less than half of 1 percentage point) and insignificant.

In relation to older workers, our initial specification reveals marginal effects for in all specifications that are small and statistically insignificant apart from perceived health risk, which is negatively signed and significant at the 10 per cent level ${ }^{13}$. In unreported specifications excluding job characteristics but including controls for gender and tenure, we find marginal effects that are negative and, with the exception of absence, statistically significant, consistent with the descriptive statistics reported earlier. However, as the results in Table 2 demonstrate, the effect of older age is essentially absent in our unadjusted models in the presence of controls for other job characteristics. Consistent with the extant literature, this would imply that older workers are typically in less risky jobs but appear to be at no greater risk when in the same job; rather it is the composition of jobs which differs.

Considering the control variables in Table 2, findings are similar to those in the existing literature. For example, females are less likely than males to perceive their health is at risk and to report experiencing injury at work. In contrast, the female coefficient shows a significant positive effect in the mental health equation (in line with Cottini and Lucifora, 2010), while women also appear more likely to report physical complaints and work-related fatigue. Consistent with other evidence in the literature, female workers exhibit higher rates of sickness absence even after controlling for a range of other personal and job characteristics.

\footnotetext{
${ }^{13}$ The marginal effects for the older age group are slightly larger in all specifications if workers aged over 65 are retained in the model.
} 
Overall, job characteristics are strong predictors of work-related health complaints. With respect to working conditions, our results indicate that workers' exposure to physical, ergonomic or psychosocial factors are positively and significantly associated with employees reporting all types of work-related health complaints. Thee effects are often large, especially in relation to physical health. For example exposure to physical risks increases the probability of (overall) perceived health risk and of health complaints by almost 19 and 18 percentage points respectively, and physical health by 17 percentage points. Ergonomic exposure increases the probability of health complaints and of physical health problems by approximately 14 percentage points in both cases. The marginal effects of psychosocial exposure are typically more modest, but as with the other exposures, statistically significant throughout.

Although not reported in detail ${ }^{14}$, our results also suggest some interesting patterns among countries. In particular, workers employed in East European countries such as Poland, Estonia, Hungary and Slovenia are more likely to consider that their health and safety is at risk and to report work-related health complaints. In Central and Northern European countries in contrast, there exists an increased probability, ceteris paribus, of reporting workrelated sickness absence.

[Table 2 here]

\subsection{Endogeneity adjusted results.}

In the top panel of Table 3, we report estimates using the IV probit model, which accounts for endogeneity of the three composite workplace risk factors. Wald statistics and the $p$-value for the test of exogeneity indicate rejection of the null hypothesis of zero correlation between the error terms from the reduced form and structural form equations, confirming the endogeneity of working conditions in all models at the 5\% significance level.

\footnotetext{
${ }^{14}$ Full results of all estimated models are available on request.
} 
The Amemiya-Lee-Newey minimum $\chi^{2}$ test of over-identifying restrictions favours combining the two instruments when controlling for endogeneity.

As can be seen however, the endogeneity adjusted results are similar to those in Table 2. The marginal effect of the younger age group on the perception of health risk increases somewhat in absolute size when controlling for endogeneity, from 2.3 percentage points in the unadjusted model to 3.3 percentage points in Table 3. Similarly, younger workers are 3.5 percentage points less likely to report work-related mental health problems when accounting for endogeneity compared with 2.8 percentage points in Table 2 . The endogeneity adjusted coefficients for older workers are likewise qualitatively unaffected and continue to reveal essentially insignificant coefficients and associated marginal effects. Marginal effects for workplace characteristics which are not reported for space reasons, also reveal the same pattern as evidenced in Table 2, virtually all being of the same sign and similar magnitude.

\subsection{Selectivity adjusted results.}

The middle panel of Table 3 reports our re-weighted models taking into account that observing only working individuals might bias our results. The participation model estimated using 2004/2005 ESS data to recover the employment probabilities used in the re-weighting procedure produces a fairly standard set of results which are documented in Table A3 in the Appendix and are not discussed in detail here. However, in terms of the two key sets of variables of interest, age and health, marginal effects show a worker aged 55-65 is some 44.0 percentage points less likely to participate than prime age individuals, while in line with previous studies, the probability of being in employment is substantially lower (31.1 percentage points) for individuals with poor health status.

The selectivity adjusted age group coefficients that are our focus continue to reveal negative and significant signs for younger workers in almost all models. However, once we 
apply our re-weighting procedure taking into account (self-)selection bias, in contrast with our earlier findings, those aged 55-65 years tend to be at higher health and safety risk. Accounting for the 'healthy worker effect' thus has a substantial and demonstrable impact on the older worker coefficients. Crucially, these observed age effects do not simply reflect the fact that older workers hold different types of jobs or live in different countries, which are captured by included occupation and other workplace characteristics variables. Rather, they indicate that those 55 and over suffer more work-related health problems. Thus, conditional on work characteristics (whose effects are essentially the same as in Table 2), older workers are 5.0 percentage points more likely to perceive their job as risky for health and safety compared with prime age workers. Additionally, the probability of reporting work-related health problems is 10.3 points higher for those aged 55-65 years (column 2). Controlling for selectivity, older workers are also significantly more likely to report work-related sickness absence (by 8.6 percentage points), as well as physical health problems, mental health problems and fatigue (7.6, 4.5 and 7.3 percentage points respectively).

These selectivity adjusted results thus reveal that accounting for the healthy worker selection effect is critical when considering the inter-relationship between work-related health and age. Marginal effects for older workers now reveal a positive and significant sign in almost all work-related health outcome models. The absence of a positive association between older workers and health at work in the unadjusted specifications reflects the exit of older workers who are more at risk, suggesting those results underestimate the true effect by not accounting for the more favourable (job) characteristics of those who remain. 


\subsection{Selectivity and endogeneity adjusted results}

Finally, in the bottom panel of Table 3 we present re-weighted and endogeneity adjusted results. Overall, the larger estimated coefficients for those aged 55-65 years seem to suggest that selection and endogeneity are likely to affect the simple probit estimates and lead to an underestimate of the true, positive effect. Controlling for both effects, younger workers are significantly less likely than prime age workers to report health problems in almost all specifications. Apart from health complaints (column 2), the marginal effect of self-reported health outcomes among the younger age group increases in absolute terms compared to the results adjusted for endogeneity only in the upper panel. For example, in the specification accounting for both endogeneity and selectivity (bottom panel) younger workers are 6.3 percentage points less likely to report work-related fatigue complaints, compared to the corresponding figure of -4.7 percentage points accounting for endogeneity only (top panel). For older workers, the marginal effects are slightly higher than the specification in the middle

panel of Table 3, suggesting that the analysis which corrects for selectivity but not endogeneity initially underestimated the effect of being in an older age group on the probability of workplace health complaints.

As before, marginal effects for workplace characteristics continue to reveal the same pattern as in the unadjusted estimation results. Thus our findings suggest that neglecting selection and endogeneity is likely to impart bias to estimates of the influence of age in particular. While the latter seems to manifest largely as a scale effect, primarily for younger workers, ignoring selection results in a qualitatively different interpretation for older workers.

[Table 3 here] 


\section{Conclusions}

This paper investigates the influence of age on work-related health in Europe using the EWCS. We focus, in particular, on the work-related health of older workers as measured by a comprehensive set of indicators including perceptions of work-related health risks, mental and physical complaints, sickness absence, injury and fatigue. After accounting for a range of employment characteristics, including detailed information on workplace conditions, initial estimates suggest older workers report no worse health outcomes than those of prime age. Young workers in contrast, are significantly less likely to report a range of adverse, work-related health outcomes.

However, we argue that evidence based purely on currently employed workers in the EWCS will be biased since it ignores an important 'healthy worker' selection effect that may operate. We anticipate that this may be particularly acute for older workers where employment is likely to be especially sensitive to health. The ESS data, which contain information on non-employed individuals, are used to re-weight the EWCS analysis to correct for sample selection. We find the results for older workers are extremely sensitive to accounting for such selection: after doing so, older workers are found to be significantly more likely to report a range of measures of adverse work-related health. The negative influence of younger workers, however, remains. The present study thus highlights the need for caution in interpretation of analyses which focus only on those currently working without accounting for such selection effects.

In addition to selection effects, the present paper also examines the possibility that older workers who remain in the workforce may have self-selected themselves into less risky jobs resulting in the endogeneity of working conditions. We find the results for older workers are not particularly sensitive to accounting for this using an instrumental variables strategy. 
The negative influence of young workers is, however, strengthened once we account for such endogeneity.

Future work should consider the robustness of these findings to the use of alternative methods to control for selection, as well as alternative measures of work-related health. Ideally studies will be able to use new data sources which, unlike the EWCS, contain objective measures of health, so resolving issues of differential (self-)reporting by age, and that also relate to and ask about work-related health for the whole population, thereby permitting researchers to capture how this affects the non-employed, and whether it is the cause of labour market exit.

In conclusion, the present findings have important implications for attempts in Europe and elsewhere to retain older workers in employment to offset the effects of population ageing. Workers who remain in employment are typically those in better health; facilitating employment for those who may otherwise may choose not to work is likely to be associated with a deterioration in work-related health outcomes, with potential costs both to individuals and employers, as well as potentially the state in providing health services. This highlights the importance of finding ways to (further) reduce the risks associated with work, as our analysis confirms the vital role of physical, ergonomic and psychosocial exposures. 


\section{References}

Amemiya, T. (1978), "The estimation of a simultaneous equation generalized probit model", Econometrica, 46: 1193-1205.

Arundel, A., Lorenz, E., Lundvall, B., and Valeyre, A. (2006), "The organization of work and innovative performance: A comparison of the EU-15," DRUID Working Papers 0614, Copenhagen Business School.

Baum, C.F., Schaffer, M.E., Stillman, S. and Wiggins, V. (2006), "overid: Stata module to calculate tests of overidentifying restrictions after ivreg, ivreg2, ivprobit, ivtobit, reg3", [URL: http://ideas.repec.org/c/boc/bocode/s396802.html]

Benjamin, K., and Wilson, S. (2005), "Facts and misconceptions about age, health status and employability," Health and Safety Laboratory, Buxton, Report HSL/2005/20.

Blanchet D. (2005), "Retirement intentions, health and satisfaction at work: an European comparison", Issues in Health Economics, IRDES N:103.

Bohle, P., Pitts, C., and Quinlan, M. (2010), "Time to call it quits? The safety and health of older workers," International Journal of Health Services, 40(1): 23-41.

Bound, J., Shoenbaum, M., Stinebrickner, T., and Waidmann,T. (1999), "The dynamic effects of health on the labour force transitions of older workers," Labour Economics, 6: 179202.

Broersen, J., De Zwart, B., Van Dijk, F., Meijman, T., and Van Veldhoven, M. (1996), "Health complaints and working conditions experienced in relation to work and age," Occupational and Environmental Medicine, 53(1): 51-57.

Butani, S. J. (1988), "Relative risk analysis of injuries in coal mining by age and experience at present company," Journal of Occupational Accidents, 10(3): 209-216.

Cai, L., and Kalb, G. (2006), "Health status and labour force participation: evidence from Australia," Health Economics, 15(3): 241-261. 
Cockerham, W., Sharp, K., and Wilcox, J. (1983), "Aging and perceived health status", Journal of Gerontology, 38(3): 349-355.

Cottini, E., and Lucifora, C. (2010), "Mental health and working conditions in European Countries," IZA Discussion Paper 4717.

de Lange, A., Taris, T., Jansen, P., Kompier, M., Houtman, I., and Bongers, P. (2010), "On the relationships among work characteristics and learning-related behaviour: Does age matter?", Journal of Organizational Behaviour, 31(7): 925-950.

Debrand, T., and Lengagne, P. (2008), "Working conditions and health of European older workers," WP IRDES N8.

Eisen, E., Wegman, H., Louis, A. (1983), "Effects of selection in a prospective study of forced expiratory volume in Vermont granite workers", American Review of Respiratory Disease, 29: 587-591.

Folkman, S., Lazarus, R., Pimley, S., and Novacek, J. (1987), "Age differences in stress and coping processes," Psychology and Aging, 2(2): 171-184.

Giniger, S., Dispenzieri, A. and Eisenberg, J. (1983), "Age, experience and performance on speed and skill jobs in an applied setting", Journal of Applied Psychology, 68(3): 46975.

Goedhart, W. (1992), "Ageing and the work environment: ageing at work", Proceedings of a European Colloquium, Paris, June 1991, Dublin: European Foundation for the Improvement of Living and Working Conditions.

Grandjean, C., McMullen, P., Miller, K., Howie, W., Ryan, K., Myers, A. and Dutton, R. (2006), "Severe occupational injuries among older workers: Demographic factors, time of injury, place and mechanism of injury, length of stay, and cost data," Nursing \& Health Sciences, 8(2): 103-107. 
Griffiths, A. (1999), "Organizational interventions: facing the limits of the natural science paradigm," Scandinavian Journal of Work, Environment and Health, 25:589-596.

Griffiths, A. (2000), "Designing and managing healthy work for older workers," Occupational Medicine, 50(7): 473-477.

Hogarth, T., and Barth, M. (1993), "Costs and benefits of hiring older workers: a case study of B\&Q," International Journal of Manpower, 12(8): 5-17.

Horvitz, D., and Thompson, D. (1952), "A generalization of sampling without replacement form a finite universe," Journal of the American Statistical Association, 47(260): 663685.

Hudak, P., Clark, J., Hawker, G., Coyte, P.,Mahomed, N.,Kreder, H., and Wright, J. (2002), "You're perfect for the procedure! Why don't you want it?" Elderly Arthritis Patients' Unwillingness to Consider Total Joint Arthroplasty Surgery: A Qualitative Study," Medical Decision Making, 22(3): 272-278.

Idler, E. (1993), "Age differences in self-assessments of health: age changes, cohort differences, or survivorship?," Journal of Gerontology, 48(6): S289-S300.

Jones, A. (2007). Applied Econometrics for Health Economists: a Practical Guide, Radcliffe Publishing Ltd.

Kalwij, A., and Vermeulen, F. (2008), "Health and labour force participation of older people in Europe: what do objective health indicators add to the analysis?," Health Economics, 17: 619-638.

Laflamme, L., and Menckel, E. (1995),"Aging and occupational accidents a review of the literature of the last three decades," Safety Science, 21(2): 145-161.

Laflamme, L., Menckel, E., and Lundholm, L. (1996), "The age-related risk of occupational accidents: the case of Swedish iron-ore miners," Accident Analysis and Prevention, 28(3): 349-357. 
Leoni, T. (2010), "What drives the perception of health and safety risks in the workplace? Evidence from European labour markets," Empirica, 37:165-195.

Li, C., and Sung, F. (1999), "A review of the healthy worker effect in occupational epidemiology," Occupational Medicine, 49(4): 225-229.

Lumsdaine, R. and Mitchell, O. (1999), "New developments in the economic analysis of retirement," Handbook of Labour Economics, 3: 3261-3307.

Mazzolini, G. (2010), "Safety at work and working conditions in Europe." DEFAP Working paper.

Mitchell, O. S. (1988), "Relation of age to workplace Injuries," Monthly Labour Review, 111(7): 8-13.

Monson, R., (1986), "Observations on the healthy worker effect", Journal of Occupational and Environmental Medicine, 28(6): 425-433.

Newey, W. (1987),"Efficient estimation of limited dependent variable models with endogenous explanatory variables", Journal of Econometrics, 36(3): 231-250.

Niedhammer, I., Chastang, J., and David, S. (2008), "Importance of psychosocial work factors on general health outcomes in the national French SUMER survey," Occupational Medicine, 58(1): 15-24.

OECD (2008), "Are all jobs good for your health? The impact of work status and working conditions on mental health", Chapter 4 (Illena-Lozal, A.), OECD Employment Outlook, OECD Paris.

Ostlin, P. (1988), "Negative health selection into physically light occupations," Journal of Epidemiology and Community Health, 42(2): 152-156.

Pailhé, A. (2005), "Working conditions: how are older workers protected in France?," Working Paper, Institut National d'Études Démographiques, Paris. 
Punnett L., (1996), "Adjusting for the healthy worker selection effect in cross-sectional studies", International Journal of Epidemiology, 25:1068-1075.

Rivers, D., and Voung, Q. (1988), "Limited information estimators and exogeneity tests for simultaneous probit models", Journal of Econometrics, 39(3): 347-366.

Robinson, A., and Smallman, C. (2006), "The Contemporary British Workplace: A Safer and Healthier Place? ", Work, Employment and Society, 20(1): 87-107.

Rogers, E., and Wiatrowksi, W. (2005), "Injuries, illnesses, and fatalities among older workers," Monthly Labour Review, 128: 24-30.

Shirom, A., Toker, S., Berliner, S., Shapira, I., and Melamed, S. (2008), "The effects of physical fitness and feeling vigorous on self-rated health", Health Psychology, 27: $567-575$.

Taimela, S., Lr, E., Malmivaara, A., Tiekso, J., Sintonen, H., Justn, S., and Aro, T. (2007), "Self-reported health problems and sickness absence in different age groups predominantly engaged in physical work," Occupational and Environmental Medicine, 64(11): 739-746.

Van den Berg, T., Schuring, M., Avendano, M., Mackenbach, J., and Burdorf, A. (2010), "The impact of ill health on exit from paid employment in Europe among older workers," Occupational and Environmental Medicine, 67: 845-852.

Viscusi, W. (2004), "The value of life: estimates with risks by occupation and industry," Economic Inquiry, 42(1):29-48.

Waddell, G., Burton, A., and Britain, G. (2006), "Is work good for your health and wellbeing?", The Stationery Office, TSO.

Warr, P. (1992), "Age and occupational well-being," Psychology and Ageing, 7(1): 37-45. 
Warr, P. (2000), "Job performance and the ageing workforce," In N. Chmiel (Ed.), Introduction to Work: A European and Organizational Psychology Perspective, Oxford, UK: Blackwell Publishers: 407-423.

Winblad, I., Jääskeläinen, M.,Kivelä, S.,Hiltunen, P.,Laippala, P. (2001), "Prevalence of disability in three birth cohorts at old age over time spans of 10 and 20 years", Journal of Clinical Epidemiology, 54(10): 1019-1024.

Wolinsky, F., Bentler, S., Cook, E., Chrischilles, E., Lie, L. Wright, K., Geweke, J., Obrizan, M., Pavlik, C., Ohsfeldt, R., and Rosenthal, G. (2009), "A 12- year prospective study of stroke risk in older Medicare beneficiaries," BMC Geriatrics: 9-17. 
Table 1: Exposure to physical, ergonomic and psychosocial risks at work

\begin{tabular}{|l|c|c|c|}
\hline Risk & Age 15-35 & Age 36-54 & Age 55-65 \\
\hline Physical & $39.1 \%$ & $35.0 \%$ & $29.0 \%$ \\
Ergonomic & $74.3 \%$ & $66.0 \%$ & $60.2 \%$ \\
Psychosocial & $82.4 \%$ & $80.7 \%$ & $77.0 \%$ \\
\hline
\end{tabular}

Notes: Percentage of persons reporting exposure to one or more risks of specified type by age group. 
Table 2: Marginal effects from work-related health outcomes probit models, EWCS 2005

\begin{tabular}{|c|c|c|c|c|c|c|c|}
\hline & $\begin{array}{l}\text { Perceived } \\
\text { health risk } \\
\text { (1) }\end{array}$ & $\begin{array}{c}\text { Health } \\
\text { complaints } \\
\text { (2) }\end{array}$ & $\begin{array}{c}\text { Mental health } \\
\text { (3) }\end{array}$ & $\begin{array}{c}\text { Physical health } \\
\text { (4) }\end{array}$ & $\begin{array}{l}\text { Sickness } \\
\text { absence } \\
\text { (5) }\end{array}$ & $\begin{array}{l}\text { Injury } \\
(6)\end{array}$ & $\begin{array}{c}\text { Fatigue } \\
\text { (7) }\end{array}$ \\
\hline \multirow[t]{2}{*}{ Female } & $-0.0336^{* * * *}$ & $0.0264^{* * * *}$ & $0.0198^{* * * *}$ & $0.0441^{* * * *}$ & $0.0123^{* * * *}$ & $-0.0346^{* * * *}$ & $0.0333^{\text {**** }}$ \\
\hline & $(0.0081)_{* *}$ & $(0.0090)$ & $(0.0046)$ & $(0.0079)$ & $(0.0042)$ & $(0.0040)$ & $(0.0075)$ \\
\hline \multirow[t]{2}{*}{ Age $15-35$} & $-0.0227^{* *}$ & $-0.0568^{\text {**** }}$ & $-0.0281^{* * * *}$ & $-0.0432^{* * * *}$ & $-0.0112^{* *}$ & 0.0048 & $-0.0418^{* * *}$ \\
\hline & $(0.0089)$ & $(0.0098)$ & $(0.0047)$ & $(0.0084)$ & $(0.0044)$ & $(0.0043)$ & $(0.0080)$ \\
\hline \multirow[t]{2}{*}{ Age 55-65 } & $-0.0272^{* *}$ & -0.0134 & -0.0047 & 0.0034 & 0.0029 & -0.0078 & 0.0017 \\
\hline & $(0.0124)$ & $(0.0138)$ & $(0.0070)$ & $(0.0124)$ & $(0.0065)$ & $(0.0059)$ & $(0.0118)$ \\
\hline \multirow[t]{2}{*}{ Tenure } & $0.0062^{* * * *}$ & $0.0099^{* * *}$ & 0.0010 & $0.0077^{* * *}$ & $0.0021^{* * *}$ & $0.0021^{* * * *}$ & $0.0036^{* * *}$ \\
\hline & $(0.0012)$ & $(0.0013)$ & $(0.0007)$ & $(0.0012)$ & $(0.0006)$ & $(0.0006)$ & $(0.0011)$ \\
\hline \multirow[t]{2}{*}{ Tenure $^{2}$} & $-0.0002^{* * *}$ & $-0.0003^{* * * *}$ & -0.0000 & $-0.0002^{* * *}$ & $-0.0001^{* * * *}$ & $-0.0001^{* * *}$ & $-0.0001^{\text {**** }}$ \\
\hline & $(0.0000)$ & $(0.0000)$ & $(0.0000)$ & $(0.0000)$ & $(0.0000)$ & $(0.0000)$ & $(0.0000)$ \\
\hline \multirow[t]{2}{*}{ Under-skilled } & $0.0422^{* * *}$ & $0.0398^{* * *}$ & $0.0144^{* *}$ & 0.0137 & 0.0044 & 0.0047 & 0.0142 \\
\hline & $(0.0126)$ & $(0.0134)$ & $(0.0070)$ & $(0.0118)$ & $(0.0062)$ & $(0.0060)$ & $(0.0113)$ \\
\hline \multirow[t]{2}{*}{ Match-skilled } & $-0.0252^{* * * *}$ & $-0.0317^{* * * *}$ & $-0.0272^{* * *}$ & $-0.0398^{* * *}$ & $-0.0102^{* *}$ & $-0.0112^{* * *}$ & $-0.0293^{\text {**** }}$ \\
\hline & $(0.0080)$ & $(0.0088)$ & $(0.0046)$ & $(0.0077)$ & $(0.0041)$ & $(0.0038)$ & $(0.0074)$ \\
\hline \multirow[t]{2}{*}{ Physical_exp } & $0.1891^{* * *}$ & $0.1767^{* * *}$ & $0.0370^{* * *}$ & $0.1711^{* * *}$ & $0.0478^{* * *}$ & $0.0718^{* * *}$ & $0.1339^{* * *}$ \\
\hline & $(0.0084)$ & $(0.0090)$ & $(0.0051)$ & $(0.0082)$ & $(0.0048)$ & $(0.0049)$ & $(0.0080)$ \\
\hline \multirow[t]{2}{*}{ Ergonomic_exp } & $0.0905^{* * *}$ & $0.1361^{* * * *}$ & $0.0255^{* * *}$ & $0.1426^{* * * *}$ & $0.0341^{* * * *}$ & $0.0514^{* * * *}$ & $0.0969^{* * * *}$ \\
\hline & $(0.0085)$ & $(0.0092)$ & $(0.0048)$ & $(0.0077)$ & $(0.0042)$ & $(0.0040)$ & $(0.0076)$ \\
\hline \multirow[t]{2}{*}{ Psychosoc_exp } & $0.0996^{* * * *}$ & $0.1254^{* * * *}$ & $0.0455^{* * *}$ & $0.0972^{* * *}$ & $0.0246^{* * * *}$ & $0.0184^{* * *}$ & $0.0852^{\text {**** }}$ \\
\hline & $(0.0086)$ & $(0.0097)$ & $(0.0045)$ & $(0.0082)$ & $(0.0043)$ & $(0.0043)$ & $(0.0078)$ \\
\hline \multirow[t]{2}{*}{ Discriminated } & $0.1766^{* * *}$ & $0.1887^{* * *}$ & $0.1340^{* * *}$ & $0.1787^{* * *}$ & $0.0797^{* * *}$ & $0.0569^{* * *}$ & $0.1499^{\text {**** }}$ \\
\hline & $(0.0173)$ & $(0.0173)$ & $(0.0133)$ & $(0.0174)$ & $(0.0111)$ & $(0.0102)$ & $(0.0167)$ \\
\hline \multirow[t]{2}{*}{ Nights } & $0.0514^{* * *}$ & $0.0612^{* * *}$ & $0.0347^{* * *}$ & $0.0337^{* * *}$ & -0.0006 & $0.0129^{* *}$ & $0.0433^{\text {*** }}$ \\
\hline & $(0.0108)$ & $(0.0118)$ & $(0.0066)$ & $(0.0103)$ & $(0.0052)$ & $(0.0051)$ & $(0.0100)$ \\
\hline \multirow[t]{2}{*}{ Evenings } & $0.0539^{* * *}$ & $0.0540^{* * *}$ & $0.0284^{* * *}$ & $0.0464^{* * *}$ & $0.0086^{*}$ & $0.0183^{* * *}$ & $0.0468^{* * *}$ \\
\hline & $(0.0090)$ & $(0.0098)$ & $(0.0052)$ & $(0.0087)$ & $(0.0046)$ & $(0.0044)$ & $(0.0083)$ \\
\hline
\end{tabular}




\begin{tabular}{|c|c|c|c|c|c|c|c|}
\hline Weekend & $0.0438^{\text {**** }}$ & $0.0468^{* * * *}$ & $0.0157^{* * * *}$ & $0.0280^{* * *}$ & -0.0041 & $0.0129^{\text {**** }}$ & $0.0349^{* * * *}$ \\
\hline \multirow{2}{*}{ Part time } & $-00451^{* * *}$ & $-00576^{\text {**** }}$ & $-00269^{* * *}$ & $-00597^{* * *}$ & $-00124^{* *}$ & (U.0042) & $0.00008^{* * *}$ \\
\hline & $(0.0111)$ & $(0.0122)$ & $(0.0057)$ & $(0.0103)$ & $(0.0052)$ & $(0.0055)$ & $(0.0099)$ \\
\hline \multirow[t]{2}{*}{ Well informed } & $-0.0717^{* * *}$ & $-0.0800^{* * *}$ & $-0.0394^{* * * *}$ & $-0.0730^{* * * *}$ & $-0.0263^{* * *}$ & -0.0069 & $-0.0632^{* * *}$ \\
\hline & $(0.0113)$ & $(0.0121)$ & $(0.0070)$ & $(0.0110)$ & $(0.0062)$ & $(0.0051)$ & $(0.0105)$ \\
\hline \multirow[t]{2}{*}{ Public } & $0.0575^{* * *}$ & $0.0318^{* * *}$ & $0.0241^{* * *}$ & $0.0247^{* * *}$ & $0.0206^{* * *}$ & $0.0122^{* *}$ & $0.0253^{\text {**** }}$ \\
\hline & $(0.0092)$ & $(0.0098)$ & $(0.0054)$ & $(0.0088)$ & $(0.0049)$ & $(0.0047)$ & $(0.0084)$ \\
\hline Firm size & Yes & Yes & Yes & Yes & Yes & Yes & Yes \\
\hline Occupations & Yes & Yes & Yes & Yes & Yes & Yes & Yes \\
\hline Countries & Yes & Yes & Yes & Yes & Yes & Yes & Yes \\
\hline$N$ & 17459 & 17459 & 17459 & 17459 & 17459 & 17459 & 17459 \\
\hline Pseudo $R^{2}$ & 0.1489 & 0.1412 & 0.1223 & 0.1669 & 0.0797 & 0.1866 & 0.1566 \\
\hline Log-likelihood & -9279.84 & -10255.11 & -5244.41 & -8785.56 & -4479.85 & -4689.70 & -8491.71 \\
\hline
\end{tabular}


Table 3: Marginal effects from work-related health outcomes, EWCS 2005

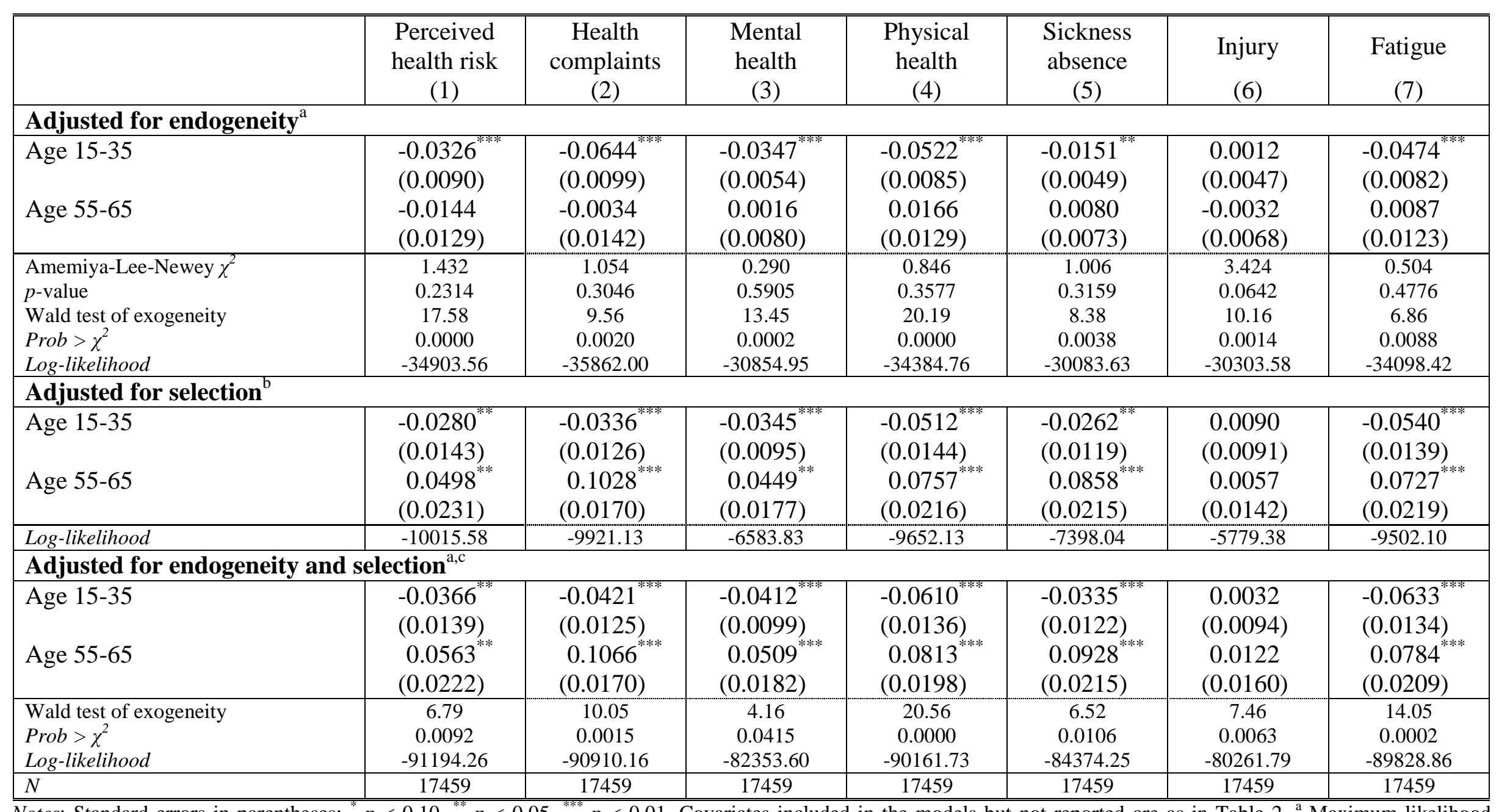

Notes: Standard errors in parentheses; ${ }^{*} p<0.10,{ }^{* *} p<0.05,{ }^{* * * *} p<0.01$. Covariates included in the models but not reported are as in Table $2 .{ }^{a}$ Maximum likelihood estimates (ivprobit in Stata 10). Amemiya-Lee-Newey test results for overidentification of instruments generated using Baum et al. (2006) overid.ado programme for Stata. ${ }^{\mathrm{b}}$ Re-weighted probit maximum likelihood estimates. ${ }^{\mathrm{C}}$ Reweighted maximum likelihood ivprobit estimates. 


\section{APPENDIX}

Table A1: Descriptive statistics, 2005 EWCS

\begin{tabular}{|c|c|c|c|c|c|c|c|c|c|}
\hline \multirow[b]{2}{*}{ Variable } & \multirow[b]{2}{*}{ Description } & \multicolumn{2}{|c|}{$\mathbf{A L L}$} & \multicolumn{2}{|c|}{ Age 15-35 } & \multicolumn{2}{|c|}{ Age 36-55 } & \multicolumn{2}{|c|}{ Age 55-65 } \\
\hline & & Mean & SD & Mean & SD & Mean & SD & Mean & SD \\
\hline \multicolumn{10}{|c|}{ Dependent variables } \\
\hline Perceived risk & 1 if respondent's health is at risk due to work & 0.294 & 0.456 & 0.305 & 0.460 & 0.296 & 0.457 & 0.238 & 0.426 \\
\hline Health complaints & 1 if work affects respondent's health & 0.363 & 0.481 & 0.353 & 0.478 & 0.379 & 0.485 & 0.307 & 0.462 \\
\hline Mental health & 1 if reports more than 2 mental complaints & 0.083 & 0.277 & 0.072 & 0.258 & 0.094 & 0.292 & 0.070 & 0.255 \\
\hline Physical health & 1 if reports more than 2 physical complaints & 0.250 & 0.433 & 0.237 & 0.425 & 0.265 & 0.441 & 0.216 & 0.412 \\
\hline Sickness absence & 1 if absence due to work-health problems & 0.079 & 0.270 & 0.076 & 0.266 & 0.084 & 0.277 & 0.066 & 0.248 \\
\hline Injury & 1 if work causes injury problems & 0.099 & 0.299 & 0.112 & 0.316 & 0.095 & 0.293 & 0.071 & 0.258 \\
\hline Fatigue & 1 if work causes fatigue problems & 0.230 & 0.421 & 0.226 & 0.418 & 0.240 & 0.427 & 0.187 & 0.390 \\
\hline \multicolumn{10}{|c|}{ Other relevant variables } \\
\hline Female & 1 if female & 0.430 & 0.495 & 0.432 & 0.495 & 0.434 & 0.496 & 0.394 & 0.489 \\
\hline Tenure & number years working with current employer & 10.121 & 9.900 & 4.103 & 4.175 & 12.811 & 9.660 & 19.220 & 13.507 \\
\hline Under-skilled & 1 if need more training to cope with work & 0.128 & 0.334 & 0.160 & 0.366 & 0.111 & 0.314 & 0.092 & 0.289 \\
\hline Match-skilled & 1 if respondent's job-skill well matched & 0.518 & 0.500 & 0.481 & 0.500 & 0.530 & 0.499 & 0.603 & 0.489 \\
\hline Physical_exp & 1 if exposed to noise, vibration, radiation etc & 0.364 & 0.481 & 0.391 & 0.488 & 0.359 & 0.479 & 0.305 & 0.460 \\
\hline Ergonomic_exp & 1 if painful position, heavy loads, standing etc & 0.691 & 0.461 & 0.733 & 0.441 & 0.675 & 0.468 & 0.645 & 0.478 \\
\hline Psychosoc_exp & 1 if work at high speed, to tight deadlines & 0.784 & 0.411 & 0.803 & 0.397 & 0.780 & 0.413 & 0.745 & 0.435 \\
\hline Discriminated & 1 if report any form of discrimination & 0.053 & 0.223 & 0.070 & 0.255 & 0.039 & 0.193 & 0.062 & 0.241 \\
\hline Nights & 1 if works at least 2 hours each month at night & 0.191 & 0.393 & 0.207 & 0.406 & 0.189 & 0.391 & 0.142 & 0.349 \\
\hline Evenings & 1 if works at least 2 hours each month at evening & 0.448 & 0.497 & 0.475 & 0.499 & 0.436 & 0.496 & 0.406 & 0.491 \\
\hline Weekend & 1 if works at least 2 hours each month weekends & 0.552 & 0.497 & 0.580 & 0.494 & 0.537 & 0.499 & 0.526 & 0.499 \\
\hline Part time & 1 if works part time & 0.151 & 0.358 & 0.140 & 0.347 & 0.146 & 0.353 & 0.224 & 0.417 \\
\hline Well informed & 1 if well informed about health and safety risk & 0.830 & 0.376 & 0.790 & 0.408 & 0.850 & 0.357 & 0.873 & 0.333 \\
\hline Public & 1 if in public sector & 0.250 & 0.433 & 0.195 & 0.396 & 0.282 & 0.450 & 0.288 & 0.453 \\
\hline Firmsize1 & 1 if between 1 and 9 employees & 0.364 & 0.481 & 0.398 & 0.490 & 0.329 & 0.470 & 0.425 & 0.494 \\
\hline Firmsize2 & 1 if between 10 and 49 employees & 0.281 & 0.450 & 0.284 & 0.451 & 0.285 & 0.452 & 0.246 & 0.431 \\
\hline
\end{tabular}




\begin{tabular}{|c|c|c|c|c|c|c|c|c|c|}
\hline Firmsize3 & 1 if between 50 and 99 employees & 0.104 & 0.306 & 0.094 & 0.292 & 0.110 & 0.312 & 0.115 & 0.320 \\
\hline Firmsize4 & 1 if between 100 and 249 employees & 0.099 & 0.298 & 0.092 & 0.289 & 0.106 & 0.308 & 0.083 & 0.276 \\
\hline Firmsize 5 & 1 if between 250 and 499 employees & 0.058 & 0.233 & 0.053 & 0.223 & 0.062 & 0.241 & 0.054 & 0.225 \\
\hline Firmsize6 & 1 if 500 and more employees & 0.094 & 0.292 & 0.079 & 0.270 & 0.108 & 0.310 & 0.077 & 0.267 \\
\hline Occupation 1 & Managers & 0.099 & 0.299 & 0.076 & 0.265 & 0.111 & 0.314 & 0.127 & 0.333 \\
\hline Occupation 2 & Professionals & 0.149 & 0.356 & 0.138 & 0.345 & 0.157 & 0.364 & 0.144 & 0.351 \\
\hline Occupation3 & Technicians & 0.135 & 0.342 & 0.137 & 0.344 & 0.135 & 0.342 & 0.130 & 0.336 \\
\hline Occupation4 & Clerical workers & 0.122 & 0.327 & 0.127 & 0.332 & 0.122 & 0.327 & 0.103 & 0.304 \\
\hline Occupation5 & Service sales workers & 0.126 & 0.331 & 0.141 & 0.348 & 0.117 & 0.322 & 0.109 & 0.312 \\
\hline Occupation6 & Skilled agricultural workers & 0.054 & 0.225 & 0.057 & 0.232 & 0.046 & 0.209 & 0.087 & 0.282 \\
\hline Occupation 7 & Craft workers & 0.141 & 0.348 & 0.149 & 0.356 & 0.140 & 0.347 & 0.115 & 0.319 \\
\hline Occupation8 & Plant and machine operators & 0.082 & 0.274 & 0.084 & 0.278 & 0.081 & 0.273 & 0.077 & 0.267 \\
\hline Occupation9 & Elementary occupations & 0.092 & 0.290 & 0.090 & 0.286 & 0.091 & 0.288 & 0.109 & 0.311 \\
\hline \multicolumn{10}{|l|}{ Countries } \\
\hline Austria & 1 if Austria & 0.012 & 0.110 & 0.013 & 0.113 & 0.013 & 0.112 & 0.006 & 0.079 \\
\hline Belgium & 1 if Belgium & 0.021 & 0.142 & 0.017 & 0.129 & 0.024 & 0.154 & 0.015 & 0.121 \\
\hline Switzerland & 1 if Switzerland & 0.021 & 0.144 & 0.020 & 0.140 & 0.021 & 0.142 & 0.031 & 0.173 \\
\hline Czech & 1 if Czech & 0.012 & 0.107 & 0.010 & 0.098 & 0.013 & 0.111 & 0.013 & 0.114 \\
\hline Germany & 1 if Germany & 0.147 & 0.355 & 0.120 & 0.325 & 0.160 & 0.367 & 0.187 & 0.390 \\
\hline Denmark & 1 if Denmark & 0.014 & 0.119 & 0.014 & 0.117 & 0.014 & 0.117 & 0.019 & 0.136 \\
\hline Estonia & 1 if Estonia & 0.002 & 0.049 & 0.002 & 0.047 & 0.003 & 0.050 & 0.002 & 0.049 \\
\hline Spain & 1 if Spain & 0.080 & 0.272 & 0.087 & 0.282 & 0.074 & 0.261 & 0.089 & 0.285 \\
\hline Finland & 1 if Finland & 0.012 & 0.111 & 0.010 & 0.102 & 0.013 & 0.114 & 0.016 & 0.127 \\
\hline France & 1 if France & 0.090 & 0.286 & 0.085 & 0.279 & 0.103 & 0.304 & 0.038 & 0.191 \\
\hline UK & 1 if $\mathrm{UK}$ & 0.138 & 0.345 & 0.128 & 0.335 & 0.137 & 0.344 & 0.185 & 0.388 \\
\hline Greece & 1 if Greece & 0.023 & 0.151 & 0.024 & 0.153 & 0.023 & 0.149 & 0.024 & 0.153 \\
\hline Hungary & 1 if Hungary & 0.022 & 0.147 & 0.025 & 0.155 & 0.021 & 0.142 & 0.019 & 0.137 \\
\hline Ireland & 1 if Ireland & 0.009 & 0.096 & 0.011 & 0.104 & 0.008 & 0.090 & 0.008 & 0.090 \\
\hline Italy & 1 if Italy & 0.098 & 0.297 & 0.096 & 0.295 & 0.099 & 0.299 & 0.096 & 0.294 \\
\hline Luxembourg & 1 if Luxembourg & 0.001 & 0.030 & 0.001 & 0.027 & 0.001 & 0.032 & 0.001 & 0.023 \\
\hline Netherlands & 1 if Netherlands & 0.041 & 0.199 & 0.038 & 0.192 & 0.042 & 0.202 & 0.047 & 0.212 \\
\hline
\end{tabular}




\begin{tabular}{|c|c|c|c|c|c|c|c|c|c|}
\hline Norway & 1 if Norway & 0.010 & 0.101 & 0.010 & 0.098 & 0.010 & 0.100 & 0.015 & 0.120 \\
\hline Poland & 1 if Poland & 0.052 & 0.222 & 0.053 & 0.223 & 0.055 & 0.227 & 0.036 & 0.185 \\
\hline Portugal & 1 if Portugal & 0.027 & 0.162 & 0.033 & 0.178 & 0.024 & 0.152 & 0.022 & 0.148 \\
\hline Sweden & 1 if Sweden & 0.024 & 0.152 & 0.018 & 0.132 & 0.024 & 0.153 & 0.045 & 0.208 \\
\hline Slovenia & 1 if Slovenia & 0.005 & 0.069 & 0.005 & 0.068 & 0.005 & 0.071 & 0.003 & 0.056 \\
\hline Slovakia & 1 if Slovakia & 0.009 & 0.093 & 0.009 & 0.095 & 0.009 & 0.095 & 0.006 & 0.076 \\
\hline Turkey & 1 if Turkey & 0.079 & 0.270 & 0.123 & 0.328 & 0.057 & 0.231 & 0.027 & 0.162 \\
\hline \multicolumn{10}{|c|}{ Instrumental variables } \\
\hline Jobqualstand & 1 if job involves precise quality standards & 0.767 & 0.423 & 0.769 & 0.422 & 0.771 & 0.420 & 0.737 & 0.440 \\
\hline Skill discretion & 1 if discretion autonomy at work & 0.538 & 0.498 & 0.503 & 0.500 & 0.550 & 0.497 & 0.589 & 0.492 \\
\hline$N$ & & \multicolumn{2}{|c|}{17459} & \multicolumn{2}{|c|}{5958} & \multicolumn{2}{|c|}{9512} & \multicolumn{2}{|c|}{1989} \\
\hline
\end{tabular}

Notes: Cross-national weights adjusted. 
Table A2: Descriptive statistics 2004/05 ESS and 2005 EWCS data

\begin{tabular}{|c|c|c|c|c|}
\hline \multicolumn{3}{|c|}{ ESS 2004/05 } & \multicolumn{2}{|l|}{ EWCS 2005} \\
\hline \multirow{2}{*}{ Variables } & \multicolumn{2}{|l|}{$\mathrm{N}=20,960$} & \multicolumn{2}{|l|}{$\mathrm{N}=17,459$} \\
\hline & Description & Mean & Description & Mean \\
\hline Female & 1 if female & $\begin{array}{c}0.447 \\
(0.497)\end{array}$ & 1 if female & $\begin{array}{c}0.430 \\
(0.495)\end{array}$ \\
\hline Age $15-35$ & 1 if aged between $15-35$ & $\begin{array}{c}0.343 \\
(0.475)\end{array}$ & 1 if aged between $15-35$ & $\begin{array}{c}0.377 \\
(0.485)\end{array}$ \\
\hline Age $35-55$ & 1 if aged between $35-55$ & $\begin{array}{c}0.544 \\
(0.498)\end{array}$ & 1 if aged between $35-55$ & $\begin{array}{c}0.531 \\
(0.499)\end{array}$ \\
\hline Age $55-65$ & 1 if aged between $55-65$ & $\begin{array}{c}0.111 \\
(0.314)\end{array}$ & 1 if aged between 55-65 & $\begin{array}{c}0.092 \\
(0.289)\end{array}$ \\
\hline Experience & $\begin{array}{l}\text { Years in employment } \\
\text { since left education }\end{array}$ & $\begin{array}{c}18.034 \\
(12.352)\end{array}$ & $\begin{array}{l}\text { Years in employment } \\
\text { since left education }\end{array}$ & $\begin{array}{c}18.454 \\
(12.087)\end{array}$ \\
\hline Married & 1 if married & $\begin{array}{c}0.598 \\
(0.490)\end{array}$ & $\begin{array}{l}1 \text { if lives with spouse or } \\
\text { partner }\end{array}$ & $\begin{array}{c}0.658 \\
(0.474)\end{array}$ \\
\hline Children & $\begin{array}{l}\text { Number of children in } \\
\text { household }\end{array}$ & $\begin{array}{c}0.679 \\
(0.778)\end{array}$ & $\begin{array}{l}\text { Number of children in a } \\
\text { household }\end{array}$ & $\begin{array}{c}0.989 \\
(1.490)\end{array}$ \\
\hline Education & $\begin{array}{l}\text { Years of education } \\
\text { completed }\end{array}$ & $\begin{array}{l}12.730 \\
(3.810)\end{array}$ & $\begin{array}{l}\text { Levels of education, } \\
\text { ISCES converted into years }\end{array}$ & $\begin{array}{l}11.847 \\
(3.121)\end{array}$ \\
\hline Good health & $\begin{array}{l}1 \text { if in excellent/very } \\
\text { good heath }\end{array}$ & $\begin{array}{c}0.769 \\
(0.421)\end{array}$ & 1 if no health problems & $\begin{array}{c}0.637 \\
(0.481)\end{array}$ \\
\hline Poor health & 1 if in bad/very poor health & $\begin{array}{c}0.023 \\
(0.151)\end{array}$ & $\begin{array}{l}1 \text { if health problems and } \\
\text { time off in last } 12 \text { months }\end{array}$ & $\begin{array}{c}0.123 \\
(0.328)\end{array}$ \\
\hline Occupation1 & Managers & $\begin{array}{c}0.095 \\
(0.293)\end{array}$ & Managers & $\begin{array}{c}0.099 \\
(0.299)\end{array}$ \\
\hline Occupation2 & Professionals & $\begin{array}{c}0.157 \\
(0.363)\end{array}$ & Professionals & $\begin{array}{c}0.149 \\
(0.356)\end{array}$ \\
\hline Occupation3 & Technicians & $\begin{array}{c}0.178 \\
(0.383)\end{array}$ & Technicians & $\begin{array}{c}0.135 \\
(0.342)\end{array}$ \\
\hline Occupation4 & Clerical & $\begin{array}{c}0.106 \\
(0.309)\end{array}$ & Clerical & $\begin{array}{c}0.122 \\
(0.327)\end{array}$ \\
\hline Occupation5 & Service \& sales & $\begin{array}{c}0.137 \\
(0.344)\end{array}$ & Service \& sales & $\begin{array}{c}0.126 \\
(0.331)\end{array}$ \\
\hline Occupation6 & Skilled \& agriculture & $\begin{array}{c}0.035 \\
(0.184)\end{array}$ & Skilled \& agriculture & $\begin{array}{c}0.054 \\
(0.225)\end{array}$ \\
\hline Occupation7 & Craft worker & $\begin{array}{c}0.131 \\
(0.337)\end{array}$ & Craft worker & $\begin{array}{c}0.141 \\
(0.348)\end{array}$ \\
\hline Occupation8 & Plant \& machinery & $\begin{array}{c}0.071 \\
(0.257)\end{array}$ & Plant \& machinery & $\begin{array}{c}0.082 \\
(0.274)\end{array}$ \\
\hline Occupation9 & Elementary & $\begin{array}{c}0.082 \\
(0.275) \\
\end{array}$ & Elementary & $\begin{array}{c}0.092 \\
(0.290)\end{array}$ \\
\hline
\end{tabular}

Notes: Standard deviations in parentheses. Samples relate to working individuals and are adjusted for crossnational weights. 
Table A3: Marginal effects from employment probability probit model, 2004/2005 ESS

\begin{tabular}{|c|c|}
\hline & (1) \\
\hline Female & $\begin{array}{l}-0.1425^{* * * *} \\
(0.0072)\end{array}$ \\
\hline Age $15-35$ & $\begin{array}{l}0.0458^{* * * *} \\
(0.0095)\end{array}$ \\
\hline Age $55-65$ & $\begin{array}{l}-0.4397^{\text {**** }} \\
(0.0117)\end{array}$ \\
\hline Experience & $\begin{array}{l}0.0233^{* * * *} \\
(0.0009)\end{array}$ \\
\hline Experience $^{2}$ & $\begin{array}{l}-0.0003^{\text {**** }} \\
(0.0001)\end{array}$ \\
\hline Education & $\begin{array}{l}0.0097^{* * * *} \\
(0.0012)\end{array}$ \\
\hline Couples/married & $\begin{array}{l}0.0311^{\text {**** }} \\
(0.0075)\end{array}$ \\
\hline Very good health status & $\begin{array}{l}0.0935^{\text {*** }} \\
(0.0084)\end{array}$ \\
\hline Poor health status & $\begin{array}{l}-0.3106^{* * * *} \\
(0.0179)\end{array}$ \\
\hline Dependent child & $\begin{array}{c}0.0067^{*} \\
(0.0045)\end{array}$ \\
\hline $\begin{array}{l}\text { Occupations } \\
\text { Countries }\end{array}$ & $\begin{array}{l}\text { Yes } \\
\text { Yes }\end{array}$ \\
\hline $\begin{array}{l}N \\
\text { Pseudo } R^{2} \\
\text { Log-likelihood }\end{array}$ & $\begin{array}{c}31825 \\
0.1895 \\
-16598.01\end{array}$ \\
\hline
\end{tabular}

Notes: Standard errors in parentheses; ${ }^{*} p<0.10,{ }^{* *} p<0.05,{ }^{* * *} p<0.01$. 